\title{
Cognitive mechanisms and emergent grammatical features in Internet memes
}

\author{
Elke Diedrichsen \\ Institute of Technology, Blanchardstown, Dublin, Ireland
}

\begin{abstract}
Internet memes of the type composed of an image macro and text, have a strong form-meaning correlation that is shared among users of social media. Their frequency of usage and the immediacy of their broad reach around the world make them an interesting field of investigation for linguistic studies. I will argue in this article that Internet memes resemble linguistic signs. Users develop a literacy, i.e. a command of their usage through convention and shared usage history. Popular Internet memes can be found in a multiplicity of variations, where details of the shown picture are changed, while the general mood or topic of the meme, mostly expressed in the caption, remains broadly the same. This article will discuss cases where the development of meme variations works along the lines of known cognitive mechanisms like metaphor and metonymy, and their prerequisites, like abstraction. Some meme variations can be represented as grammaticalisation paths that lead to the emergence of grammatical features like morphemes.
\end{abstract}

Keywords: Internet memes, emergent grammar, grammaticalisation, metaphor, metonymy

\section{Introduction: Memes are signs in human interaction}

Richard Dawkins (1976) famously describes memes as the cultural equivalent of biological genes: A meme is a unit of human culture. It is comparable to a gene in that cultural units are passed on to other members of the culture. They may undergo variation, and there is competition among cultural units as some will be adopted and sustained within the culture, while others are not considered useful or interesting enough and will be forgotten by the next generation. Dawkin's examples of memes comprise pieces of music, linguistic theories, fashion trends, religious beliefs and ceremonies and the like. They also involve applied knowledge shared among humans, like knowledge about making pots, for example. There is a research area called 'memetics' that explores the insights to be gained from a comparison of cultural units and biological genes (see e.g. Blackmore 1999 and the contributions to the "Journal of Memetics" that appeared from 1999 through 2005 and is available online). Critiques of this approach maintain that cultural production and interaction cannot be easily broken down to 
an exchange of "units" (Cannizzarro 2016, Shifman 2014). Producers of cultural content, which are human beings, should not be seen as mere 'carriers' of the content, but as wilful agents who select, alter and remove cultural material in their interactions and perceptions. This happens according to their free will, but also in relation to peer pressure, and requirements posed by the situational and general context.

I have, however, argued elsewhere (Diedrichsen 2013a, 2013b, forthcoming) that the term 'meme' is useful for the description of signs in human communication, as it opens up the explanation of the communicative potential of signs beyond the limiting boundary of the concept of a 'word', and in fact beyond the realm of mere written forms of linguistic expression. Any sign in human communication, of any shape, is a cultural unit. It emerges through usage (Wittgenstein 1960, Eco 1976, Feilke 1996, 1998, Everett 2012). The form and meaning of a sign is shaped and defined by usage conventions, which are acquired through interactions within a culture, and are therefore transient and subject to change. The same holds for structures and routines of linguistic expression. They are generated in interaction, as well. Before an individual interaction, structures and routinized norms may be known by interlocutors, but this is so because they have a "living historical continuity of interaction" (cf. Hopper 2011, Linell 1998: 59-60). So there are norms and structures in language, but they exist because interactants have come to know them through the interaction in a culture. Emergent grammar means that grammatical categories and structures do not freeze once they are established (Hopper 2011). They are, rather, being reinterpreted, modified and negotiated in every interaction. Note that this is the case for the shared knowledge base that underlies human communication as well: As Kecskes and Zhang (2009) point out, there is core and emergent common ground. While core common ground is a reliable source of mutually shared knowledge, some knowledge needs to be negotiated and confirmed in interaction. This is fleeting, unstable, situational knowledge that is not necessarily taken for granted by any of the interlocutors.

This paper will be concerned with Internet memes. Their appearance as a social media phenomenon, their conventionality and the regularities of their variation will be analysed from a linguistic point of view. The research questions underlying this analysis are the following: Can variations in Internet meme appearances be linked to cognitive mechanisms and to linguistic processes that lead to the emergence of new forms, like grammaticalisation? Can parts of memes consequently be described in terms of grammatical categories, like morphemes?

The paper will proceed as follows: Section 2 will define Internet memes and give a short characterization of their communicative potential. Section 3 will give an overview of the formal variation found in Internet memes and relate them to grammaticalisation processes.

\section{Internet memes}

Internet memes are signs that follow conventions. They are used for communication. It has been argued that the interaction with Internet memes should be described as phatic: In phatic communication, it is the participation that counts, rather than the delivery of a message (Milner 2012). 
Internet memes are contentful objects of diverse shapes that are spread across Social Media in order to attract viewers and invite them to produce related content, mostly with the intention of being funny or making a comment about an aspect of life in general or popular culture. Meme usage has aspects of communicative interaction, because memes have established conventions of usage. They are produced for an audience in order to spark reactions, and they are viewed against the background of a culture of meme usage.

Each meme has its own topic, refers to a certain circumstance, mood or attitude that other users can relate to. Within this broad topic area, users are free to create variations and combinations of memes. Digital communities have "sets of unwritten rules for proper memerelated conduct" (Katz and Shifman 2017: 828). The site knowyourmeme.com serves as a reference that formulates current proper usage of memes. "Becoming literate in these groups is a phatic process, since levels of meme literacy serve as cultural capital, differentiating members from non-members." (Katz and Shifman 2017: 828, see also Nissenbaum and Shifman 2015, Miltner 2014).

The aspect of global phatic communication via the Internet, the experience of making communicative interaction possible in real time with multiple participants around the world, and interactively inventing signs, rules and conventions, has led me (Diedrichsen forthcoming) to the following definition of memes, which is a slight variation from the definition offered by Shifman (2014: 41):

One meme is:

a) A group of digital items which share common characteristics of content, form, and/or stance

b) Users create these items with the intention to make them interact with and react to each other

c) The items are circulated, imitated, and/or transformed via the Internet by many users.

The semantics of memes is mainly informed by participating users' relevant cultural knowledge (interests relating to age group, pop culture, country and culture of origin, familiarity with technology and internet, relation to sentiments shared by users, like the love of cats or the appreciation of certain films and their characters). The form of memes is mainly shaped by the technically feasible, with respect to the publishing source and the capability and motivation of users to generate content, but also by trends and existing forms of memes. An important aspect in the creation of memes is also the desire to attract attention, which is achieved by the choice of topic, use of colours, recognisable image structures, bold letters, and the size of the image in this digital linguistic landscape (Diedrichsen forthcoming).

\section{A arammar of Internet memes?}

Internet memes are a very popular and observable example of how signs and sign variations emerge through usage. They are created in real time by Internet users, and any new creation is attested on the Internet. The Internet is a medium where the creation of content leads to immediate mass distribution, and the extent to which it is received is unpredictable. Also, any reaction to the content can be immediate. There is a steady stream of new picture- and text combinations that may become memes if they catch on with users and attract many variations. The form of the meme is varied and generally unpredictable. A variety of meme genres have 
been listed and explained by Shifman (2014: 108-115). Any list of memes will be preliminary, however, because memes keep emerging, and taking on new shapes, such that there cannot be any definite description of the form a meme can take. I will limit the discussion in this paper to one very popular meme genre, that is called stock character macros or Advice Animals. These are images that show a character or animal on a coloured background with a caption in white bold text. The descriptions of these memes are available via a database search for the meme name in knowyourmeme.com.

I will argue in this paper that the variations undergone by memes show features that are reminiscent of cognitive mechanisms related to grammaticalisation processes and emergent grammatical categories in language.

\subsection{Grammaticalisation: The emergence of grammatical categories}

Grammaticalisation is a process by which linguistic elements with no or little grammatical function obtain more grammatical function or the grammatical function gets established in the first place. The process of the establishment of a grammatical function frequently happens through reanalysis, which is a metonymical process. A given structure obtains a new interpretation in terms of the functions of its elements. This happens in circumstances where the interpretation of the structure is ambiguous. The result of a reanalysis is a new interpretation of the given structure. This new interpretation is not obvious on the structure, unless it is applied to variations of the structure. The re-application of the new interpretation is called analogy, and analogy is guided by metaphor. Analogy makes the changes that have taken place in reanalysis observable. Reanalysis and analogy are the major mechanisms in language change, and grammaticalisation does not occur without them (Hopper and Traugott 1993: 61-62). Metaphor and metonymy are mechanisms used by human cognition for problem solving.

\footnotetext{
'The main direction of both types of problem solving is toward informativeness, but the two types correlate with shifts along different axes. Metaphorical change involves specifying one, usually more complex, thing in terms of another not present in the context. Metonymic change, on the other hand, involves specifying one meaning in terms of another that is present, even if only covertly, in the context. It is largely correlated with shifts to meanings situated in the subjective belief state or attitude toward the situation, including the linguistic one. While metaphor is correlated primarily with solving the problem of representation, metonymy and lexicalizing of conversational meanings are correlated with solving the problem of expressing speaker attitudes.'
}

(Hopper and Traugott 1993: 87).

One famous example of the effect that can be brought about by reanalysis and analogy is the emergence of the English going to future. It will be explained here shortly, and after that I will proceed to discuss the application of the terms reanalysis and analogy to processes going on with memes. The discussion will lead me to the conclusion that the cognitive mechanisms metaphor and metonymy apply to the description of meme variation, and that in some cases one can identify grammaticalisation processes that result in the emergence of morphological and syntactic categories. 


\subsection{The grammaticalisation process of the English going to future}

The grammaticalisation of the English going to future comes about because there is a future component existent in the interpretation of going to even in its literate, full verb reading: A statement about going somewhere involves that the arrival at that location will be in the future.

(1) a. I am going to London.

b. I am going to visit Bill.

c. I am going to like Bill.

d. I am gonna like Bill.

If I say the sentence in (1a), I will arrive in London in the future. Here, the full verb use of going to is obvious because there is no other verb in the sentence. The full verb use is less obvious if the specification of the destination involves another verb, as in (1b). Here, it is possible to understand the sentence in a similar sense as (1a), which is 'movement to a place where Bill lives', which implies that the speaker will see Bill in the future. The fact that there are two verbs in the sentence, however, might lead the interpreter to a reading where going to is a future auxiliary and visit Bill is the intention projected into the future. Auxiliaries exist in English, therefore this assumption would not require the invention of a whole new grammatical category. The ambiguity of the verb function is the first stage in the grammaticalisation process. In the future reading, a reanalysis of the structure has taken place, where going to is not a motion verb and visit Bill is not a place, which would be the interpretation to be gained from a full verb reading. The fact that the reanalysis has taken place is, however, not visible in the structure. It becomes obvious when the new structural interpretation is applied to new uses of be going to, where the interpretation of 'motion to a place' is not possible, as in (1c). In a further step, the complex auxiliary be going to becomes a single morpheme, gonna, by phonetic reduction. According to Hopper and Traugott (1993:61), the process behind this is again reanalysis.

Table 1: The grammaticalisation path of the going to future (after Hopper and Traugott 1993: 61)

\begin{tabular}{|c|c|c|}
\hline Grammaticalisation stage & Perceived Structure & Mechanism for interpretation \\
\hline Stage 0 & I am going [to London] & $\begin{array}{l}\text { Full verb reading of going: motion verb } \\
\text { To London: Specification of destination }\end{array}$ \\
\hline Stage 1 & I am going [to visit Bill] & $\begin{array}{l}\text { Ambiguous structure with two verbs. } \\
\text { Full verb reading of going: motion verb } \\
\text { In analogy with stage } 0 \text {, the purposive clause to visit Bill } \\
\text { is interpreted as a specification of destination. }\end{array}$ \\
\hline Stage 2 & I am [going to] visit Bill & $\begin{array}{l}\text { Reanalysis of the ambiguous structure: } \\
\text { Going to: Future auxiliary } \\
\text { Visit: Activity verb, }\end{array}$ \\
\hline Stage 3 & I am [going to] like Bill & $\begin{array}{l}\text { Analogy: going to as a future auxiliary is used with a } \\
\text { stative verb, which is possible, as the auxiliary reading } \\
\text { of going to does not require any implication of change } \\
\text { of place }\end{array}$ \\
\hline Stage 4 & I am [gonna] like/visit Bill & $\begin{array}{l}\text { Reanalysis: The complex auxiliary is reduced to a single } \\
\text { morpheme; any ambiguity is removed. }\end{array}$ \\
\hline
\end{tabular}




\section{Emergent grammar and grammaticalisation processes in Internet memes}

This section will introduce a few cases of grammaticalisation in terms of emergent grammatical categories in memes. It can be shown that the frequency of usage and the multiplicity of variations that the memes are subjected to bring about shifts in the functionality of pictorial elements that can be described along the lines of grammaticalisation processes as outlined in section 3.

The viral nature of the memes involves their recognisability, but some variation as well, as they are applied to new stories within the same broad topic area. In the creation of new meme variations, it happens that some formal elements are retained and others are altered in a generally straightforward fashion. Here, I will mainly talk about changes that resemble the emergence of new morphemes, but it will be argued at the end of the paper that instances of syntactic organisation can be found in meme usage as well.

A reviewer remarks that the formal variation in memes should not be described as grammaticalisation processes involving, for example, morphemes, but rather as developments that resemble grammaticalisation processes with features that resemble morphemes. I have made the point here that Internet memes can be treated analogous to linguistic signs because of their communicative nature and their conventionality. I am arguing that like linguistic signs, Internet memes are cultural units that evolve and spread among a community of users, and that their usage and development are subject to communicative demands. With that analogy in mind, I am proceeding to regard formal developments and shifts in interpretation along the lines of grammaticalisation processes. This involves the assumption that in some cases the emergence of units carrying meaning and forming new complexes can be described as grammaticalisation processes leading to the formation of morphemes. Note that morphology and the description of morphemes is not restricted to spoken and written words in linguistics. Sign languages that are visual-gestural and have no spoken or written forms do have rich inflectional morphology in terms of hand shapes, hand movement, facial expressions and other visible articulators (Leeson and Saeed 2012). It is with regard to this broader view of communicative means that I describe the features and processes analysed here, using linguistic terminology for a phenomenon that I consider to be a linguistic one, but in a broader sense that extends beyond the realm of words and sentences.

\subsection{Meme: Roll Safe}

This meme was very popular around the beginning of the year 2017. It involves a picture of a character called Roll Safe from the web series Hood Documentary, smirking and pointing his finger at his temple. The text jokingly points out a kind of reasoning where a circumstance is avoided by removing its necessary and sufficient condition (NSC). This meme has undergone some variation, but certain elements of the meme remained unaltered. Viewing memes and their instantiations as complex signs, as pointed out above, I give an overview of their features in terms of the main areas of linguistic description, morphology, semantics, and pragmatics. The semantics part describes the meaning and propositional content of the meme, as it has been conventionalised over manifold instances of usage, and as it is described in 
www.knowyourmeme.com. The pragmatics part involves the communicative function that can be associated with the meme. The morphology part works on the claim made here that morphemes emerge and can be isolated in the analysis of memes. Note that the discovery of morphemes involves an analytical observation of a variety of instances of a meme, such that it becomes obvious which is the part of the meme that gets transferred to other variations of the meme, and carrying semantics in the course of this transferral. I will provide a constructional schema for every meme discussed here, that informs about these features. Note that an important area of linguistic investigation, syntax, is left out here, because we discuss memes as singular items. The possibility of analysing combinations of meme contents will be left for future work.

Table 2: Constructional Schema for Roll Safe meme

\begin{tabular}{cll}
\hline Meme: Roll Safe & Morphology & $\begin{array}{l}\text { Morpheme: 'Finger-to-temple' gesture } \\
\text { The same gesture is used in different variations of the meme. }\end{array}$ \\
Semantics & $\begin{array}{l}\text { Joke relating to a kind of reasoning where a circumstance is avoided by } \\
\text { removing its condition. The gesture signifies that reasoning is involved. }\end{array}$ \\
Pragmatics & $\begin{array}{l}\text { Irony, mockery: The reasoning portrayed in the meme is stupid and } \\
\text { nonsensical, applies to losers' }\end{array}$ \\
\hline
\end{tabular}

The images in Figures 1-5 show instances of the Roll Safe meme. We need to look at a few instances in order to see what variations occur. Comparing the images, it becomes clear that the caption expresses variations on an ironic reference to a kind of reasoning where a circumstance is avoided by removing its NSC. The characters used in the meme change, but what remains constant is the finger-to-temple gesture. Compare the following images:

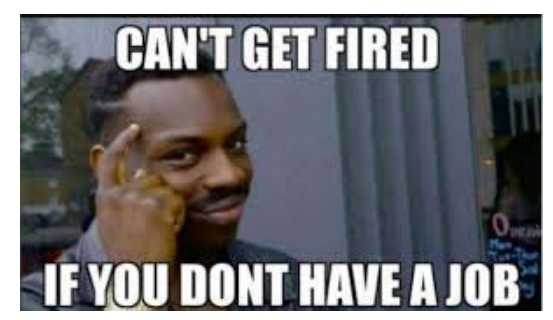

Figure 1: Roll Safe Job

(http://thinkingmeme.com/top-24-roll-safe-meme/ Last accessed 17 January 2018)

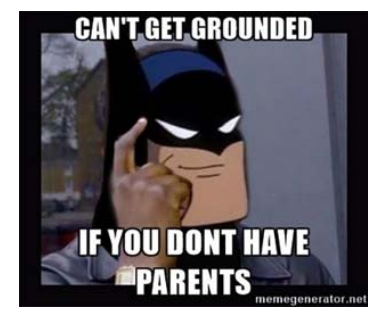

Figure 3: Roll Safe Batman

(http://thinkingmeme.com/top-24-roll-safe-meme/ Last accessed 17 January 2018)

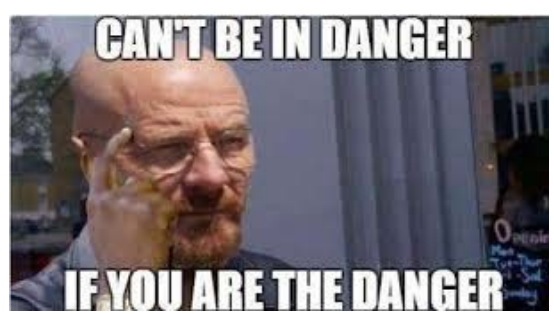

Figure 2: Roll Safe Walter White (http://thinkingmeme.com/top-24-roll-safe-meme/ Last accessed 17 January 2018)

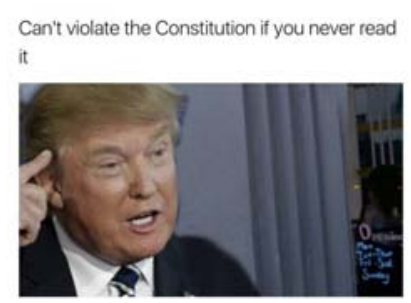

Figure 4: Roll Safe Trump (http://thinkingmeme.com/top-24-roll-safe-meme/ Last accessed 17 January 2018) 


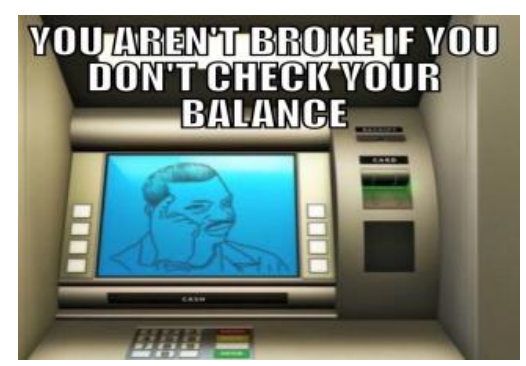

Figure 5: Roll Safe balance (http://www.ebaumsworld.com/pictures/14-of-the-best-roll-safememes/85257795/ Last accessed 17 January 2018)

From the observation that the pointing gesture reappears in variations of the meme, carrying the meme semantics, we conclude that this gesture is acting like a morpheme. Note that the usage of this gesture as main contributor to the expressive power of the meme was predictable, as there is a convention for the same interpretation of this pointing gesture available in our culture. The gesture is a known and well used metaphor for a certain mindset that involves reasoning, and it can be used either seriously or ironically. From the original image featuring Roll Safe and its gesture, the grammaticalisation path towards the morphological function of the gesture can be outlined as in Table 3 .

Table 3: Grammaticalisation path for Roll Safe meme

\begin{tabular}{llll}
\hline $\begin{array}{l}\text { Grammaticalisation } \\
\text { stage }\end{array}$ & Picture & Perceived Structure & Mechanism for interpretation \\
\hline Stage 1 & $\begin{array}{l}\text { Figure } \\
1\end{array}$ & $\begin{array}{l}\text { [Character called Roll Safe from web } \\
\text { series Hood Documentary smirking } \\
\text { and pointing his finger at his temple] }\end{array}$ & Full image carries meme semantics \\
\hline Stage 2 & $\begin{array}{l}\text { Figure } \\
1\end{array}$ & $\begin{array}{l}\text { Character called Roll Safe from web } \\
\text { series Hood Documentary smirking } \\
\text { and [pointing his finger at his temple] }\end{array}$ & $\begin{array}{l}\text { Reanalysis [metonymical]: The meme } \\
\text { semantics lies in the pointing gesture, } \\
\text { the character could be replaced. This } \\
\text { interpretation is not random, as there } \\
\text { is an existing meaning convention for } \\
\text { the pointing gesture }\end{array}$ \\
& Figure \\
Stage 3 & $\begin{array}{l}\text { Any character pointing their finger at and } \\
\text { the temple }\end{array}$ & $\begin{array}{l}\text { Analogy [metaphorical]: The pointing } \\
\text { gesture can be used on any character, } \\
\text { and carries the meme semantics by } \\
\text { analogy }\end{array}$ \\
\hline
\end{tabular}

\subsection{Meme: Scumbag Steve}

Scumbag Steve is a meme that is very well known and can almost be considered a classic within meme/popular culture. The meme started spreading and peaked in the year 2011, according to Google Trends and knowyourmeme.com, but it is still widely known and appears in social media from time to time. The photo displayed in the meme shows a young man with an iconic brown cap worn sideways, a golden chain around his neck and an open brown coat with a furry hood, who stands in a doorframe. The text shown in the meme characterises this person as someone who shows mean, antisocial behaviour. In the course of the usage of this meme, variations occur that explain different situations where someone has shown antisocial 
behaviour. Interestingly, some variations also alter the composition of the picture in that one element is singled out to carry the 'scumbag' semantics to alternative situations. It turns out that the element that is interpreted as the carrier of the 'scumbag' semantics is the hat, and it may be placed elsewhere, for example on objects, in order to express that these are malfunctioning. The process of reinterpreting the whole meme in such a way that the hat becomes the main carrier of the 'scumbag' semantics is a double metonymic expansion as described by Ruiz de Mendoza and Galera (2014: 119-123): The hat stands for the wearer, and, in terms of the AGENT FOR ACTION metonymy, for the behaviour of the wearer. As there is no existing convention for a brown cap to signify mean behaviour, this grammatical feature can be said to have emerged through usage.

Table 4 shows the Constructional Schema of the meme, that explains its semantic, morphological and pragmatic features, based on observations made in a picture selection as it is exemplified in Figures 6-11. There are variations of Scumbag Steve featuring an empty doorway, that imply that Scumbag Steve is gone when you need him (cf. Figure 12). I have not found any instance of a 'scumbag' meme featuring one of the other details seen in the Scumbag Steve meme, like a furry coat, or a golden necklace.

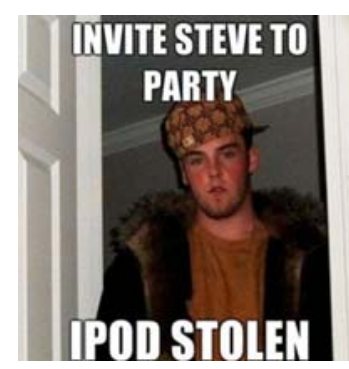

Figure 6: Scumbag Steve iPod stolen

(http://www.lolriot.com/scumbag-stevecompilation-20-images/scumbag-steve-invitesteve-to-party-ipod-stolen/ Last accessed 23 January 2018)

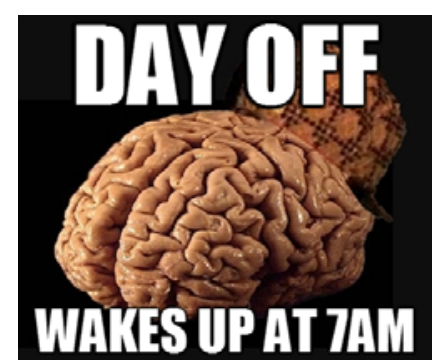

Figure 8: Scumbag Brain

(https://goo.gl/images/XF88jE Last accessed 23 January 2018)

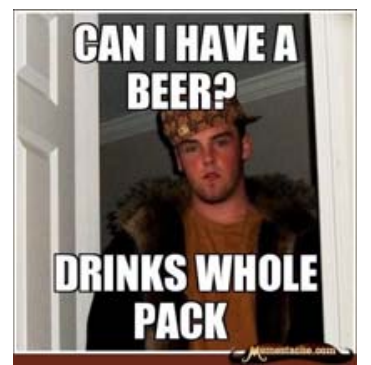

Figure 7: Scumbag Steve beer (https://goo.gl/images/tK5ebR Last accessed 23 January 2018)

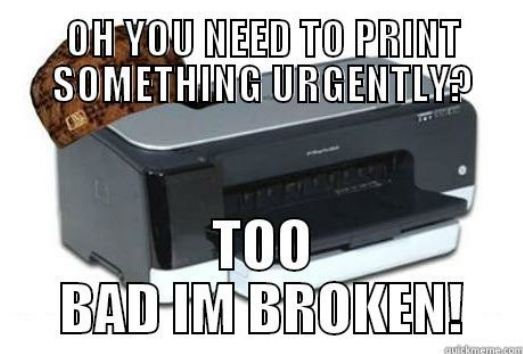

Figure 9: Scumbag Printer

(https://goo.gl/images/eB683t Last accessed 23 January 2018) 


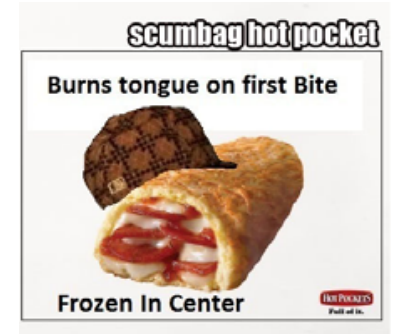

Figure 10: Scumbag Hot Pocket

(https://goo.gl/images/eilREN Last accessed 23 January 2018)

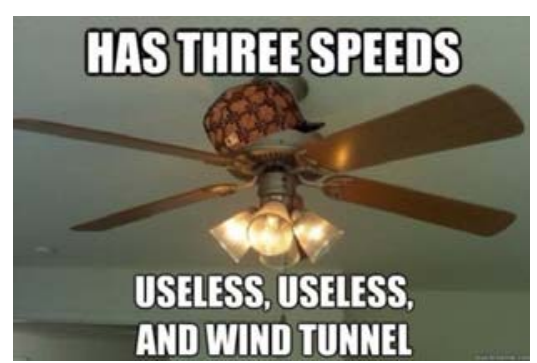

Figure 11: Scumbag ceiling fan

(https://goo.gl/images/bPjaTu Last accessed 23 January 2018)

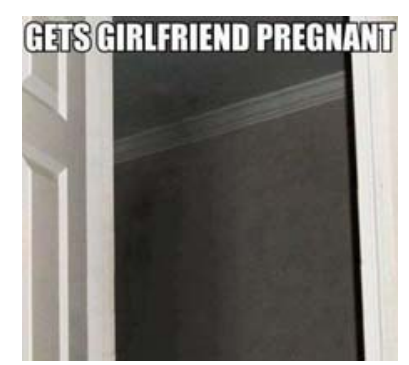

Figure 12: Scumbag Steve Doorway (http://i0.kym-cdn.com/photos/images/original/000/545/804/775.jpg Last accessed 23 January 2018)

Table 4: Constructional schema for Scumbag Steve meme

\begin{tabular}{lll}
\hline $\begin{array}{l}\text { Meme: } \\
\text { Scumbag Steve / }\end{array}$ & Morphology & $\begin{array}{l}\text { Morpheme: brown cap } \\
\text { The cap is used in different variations of the meme, and it is used } \\
\text { Scumbag Hat }\end{array}$ \\
& $\begin{array}{l}\text { Semantics } \\
\text { independently in a meme of its own, to signify mean behaviour of objects }\end{array}$ \\
& Person behaving mean and egoistic, antisocial, also: malfunctioning objects \\
\hline
\end{tabular}

From the original image featuring the young man called Scumbag Steve, the grammaticalisation path towards the morphological function of the hat can be outlined as shown in Table 5. Figure 12 does not appear on this grammaticalisation path, as it is a deviation from the general tendency to let the hat appear in images to carry the Scumbag Steve semantics. It demonstrates, however, that the choice of the hat is indeed random, and the detail singled out could have been anything in the original picture, like the doorway, for example. Because of the emergent nature of meme creation, this may certainly still happen. For the majority of variations of the Scumbag Steve meme, it is currently the hat that ascribes 'scumbag' behaviour to everyone and everything one wants, or rather, everything that can be pictured. This fact has been noticed by users and made into a meme (Figure 13).

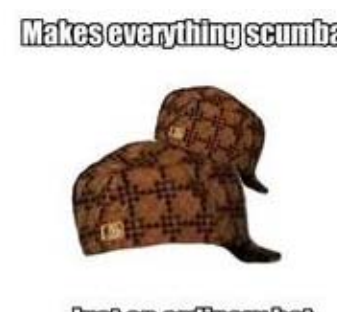

Figure 13: Scumbag Meta comment (https://goo.gl/images/LfPjEf, last accessed 23 January 2018) 
Table 5: Scumbag Steve/Scumbag Hat: Grammaticalisation path

\begin{tabular}{|c|c|c|c|}
\hline $\begin{array}{l}\text { Grammaticalisation } \\
\text { stage }\end{array}$ & Picture & Perceived Structure & Mechanism for interpretation \\
\hline Stage 1 & $\begin{array}{l}\text { Figure } \\
6-7\end{array}$ & $\begin{array}{l}\text { [Young man with a furry coat, a } \\
\text { golden necklace and a brown cap } \\
\text { standing in a doorway] }\end{array}$ & Full image carries meme semantics \\
\hline Stage 2 & $\begin{array}{l}\text { Figure } \\
6-7\end{array}$ & $\begin{array}{l}\text { Young man with a furry coat, a } \\
\text { golden necklace and [a brown cap] } \\
\text { standing in a doorway }\end{array}$ & $\begin{array}{l}\text { Reanalysis [metonymical]: The meme } \\
\text { semantics lies in the brown cap, the } \\
\text { character and other details could be } \\
\text { replaced/discarded. } \\
\text { This interpretation is random: There is } \\
\text { no existing meaning convention for the } \\
\text { brown cap }\end{array}$ \\
\hline Stage 3 & $\begin{array}{l}\text { Figure } \\
8-11\end{array}$ & $\begin{array}{l}\text { Any character or object with the } \\
\text { brown cap }\end{array}$ & $\begin{array}{l}\text { Analogy [metaphorical]: The brown cap } \\
\text { can be used on any character or object, } \\
\text { and carries the meme semantics }\end{array}$ \\
\hline Stage 4 & $\begin{array}{l}\text { Figure } \\
8-11\end{array}$ & $\begin{array}{l}\text { The brown cap as a meme of its } \\
\text { own } \\
\text { (cf. knowyourmeme.com) }\end{array}$ & $\begin{array}{l}\text { Reanalysis: The brown cap on its own is } \\
\text { "Scumbag Hat", the complex 'Scumbag } \\
\text { Steve' meme is reduced to a simple item } \\
\text { that acts as a morpheme (cf. Hopper and } \\
\text { Traugott 1993: 61, where the reduction } \\
\text { from going to to gonna is described as } \\
\text { reanalysis as well) }\end{array}$ \\
\hline
\end{tabular}

\subsection{Meme: Arthur's Fist}

We have noted in the discussion of the Scumbag Steve meme that the abundance of variations on memes may involve creations that make a meta-comment about the meme itself, in terms of ridiculing its content or the way it is displayed. One meme whose instantiations show such meta comments quite frequently is the Arthur's Fist meme. Arthur's Fist shows a screenshot from the children's television series called "Arthur", in which the protagonist animated character clenches his right fist, while wearing a yellow sweater and blue trousers.

In the meme, this image appears with captions that describe situations in which the user suppresses disappointment or other negative emotions. The image was first used as a meme in late summer 2016, and its search interest peaked between July and October 2016 (knowyourmeme.com, Google Trends). Arthur's Fist is not easily described in terms of emergent morphology. It turns out that the many meta variations that occur with this meme do not single out one element only. The obvious candidate for a morpheme carrying the semantics of the whole meme would be the fist itself, as it is the most prominent element in the picture. Also, a clenched fist is a known indicator of suppressed emotions. It is an indexical sign. In the meme, it has a metonymical relationship towards the kind of emotion that it is supposed to express. Metonymies play an important role in structuring emotion categories (Ungerer and Schmid 1996: 128). The attempt at keeping a negative emotion under control is part of the emotion scenarios provided by Lakoff 1987: 377ff. and Kövecses 1990, cf. also Ungerer and Schmid 1996: 141), and its visible physical symptom is the clenched fist. 
In the Arthur's Fist meme, the relationship between signifier and signified does not emerge through convention, as it is the case with Scumbag Hat, for example. Rather, users know from experience that a clenched fist can be part of a frustrating situation, and they know from media experience that the display of a clenched fist can signify suppressed frustration by metonymy, like a red, steaming head, shown in a comic, for example, can signify anger.

In variations of the meme, multiple elements of the image undergo variations. The meme appears with a clenched left fist, with fists belonging to other characters known from television series or movies, like Spongebob or Hulk, the fist may have a dark skin colour, or it may not be seen because the arms of the sweater are too long (cf. knowyourmeme.com and Google images for samples of the meme). The caption in these images generally expresses frustration, which bears a relation to the way the image is altered. There are also instances of the Arthur's Fist meme where the modality of the image representation changes, as shown in the examples below. From my observation, an unusually high number of variations of the Arthur's Fist meme acts as a meta-comment, in that the caption makes a comment that is reflected in the picture. It seems that with this meme, phatic communication in the sense of displaying insider knowledge, playful variation of and reaction to a picture, is realised to a very strong degree. Many instances of the meme (cf. Figures 16-19) are self-referential, in that their main function is a playful variation of the picture components, rather than a comment about a state of affairs in the world. Many memes do not 'make sense' in terms of referring to the outside world, but rather represent jokes in and by themselves (see Katz and Shifman 2017 for a discussion and examples).

The constructional schema in Table 6 shows the formal, semantic and pragmatic properties of the meme Arthur's Fist, based on observations made in a picture selection as it is exemplified in Figures 14-19.

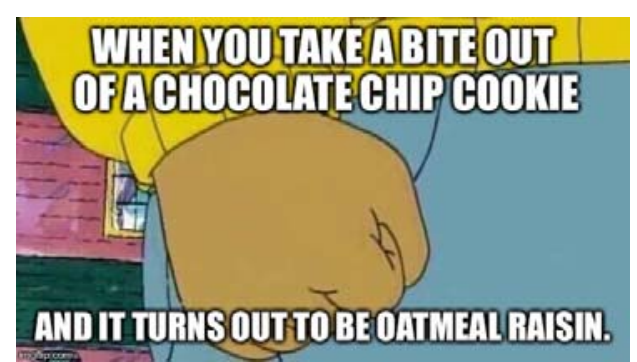

Figure 14: Arthur's Fist Oatmeal Raisin (https://imgflip.com/i/1lobde Last accessed 20 December 2017)

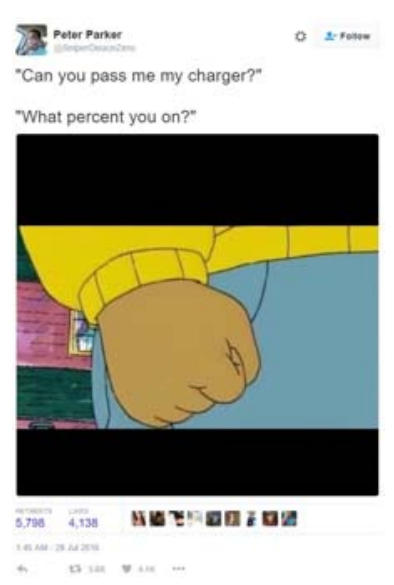

Figure 15: Arthur's Fist charger (https://goo.gl/images/jBujU9 Last accessed 28 January 2018) 


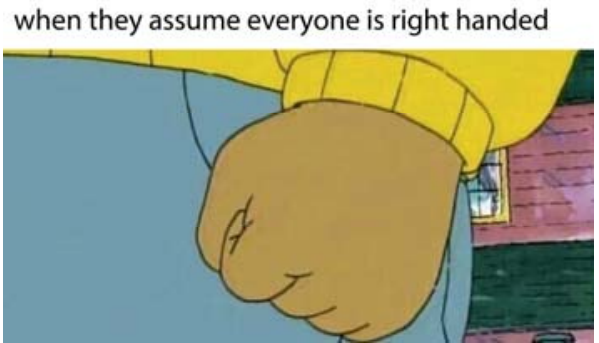

Figure 16: Arthur's Fist left handed

(https://goo.gl/images/t5q8bT Last accessed 28 January 2018)

when he tells you you're too old to play with lego

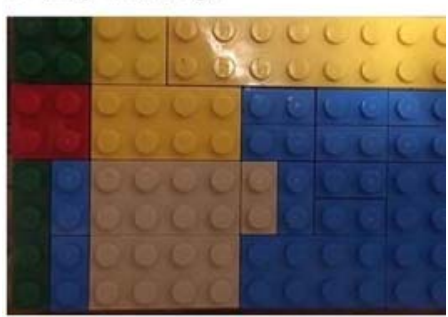

Figure 18: Arthur's Fist lego

(https://goo.gl/images/LMhjDo Last accessed 28 January 2018)
When your mom buys you a sweater that's too big

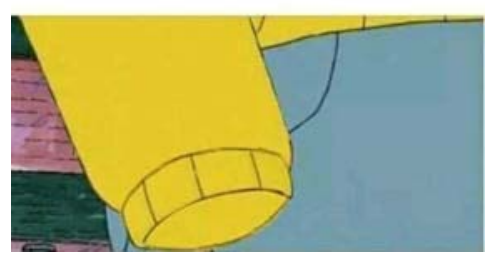

Figure 17: Arthur's Fist sweater (https://goo.gl/images/vVRx1N Last accessed 28 January 2018)

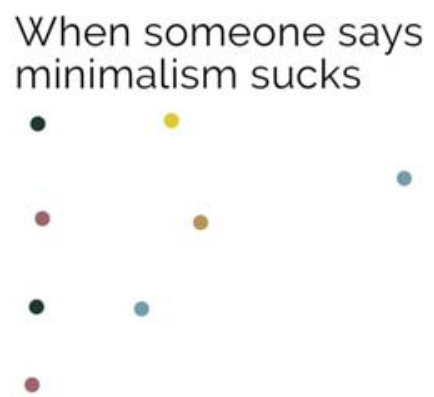

Figure 19: Arthur's Fist minimalism (https://goo.gl/images/c3SgMT Last accessed 28 January 2018)

Table 6: Constructional schema for Arthur's Fist meme

Meme: Arthur's Fist Morphology Clenched fist in yellow sweater

Colour combination of yellow, blue and brown-ish (skin-colour); green and pink in the background.

These components reappear across replications of the meme

Semantics Something happens that speaker does not like, and their helpless response is a clench of the fist.

Pragmatics Complaint, expression of helplessness, often: meta comment, play with components and modality of the picture, phatic communication

In the variations on Arthur's Fist meme, it is not easy to identify a direction of development. The instances of the meme show variations not only on disappointing situations in the world that one might suffer, but also on the topic 'fist' itself, and the mode of image representation found in the meme. In the variation schema presented in Table 7, that is not quite a grammaticalisation path, three lines of development are distinguished: The first one describes the statement the meme makes about disappointments in the world, the second one sees the 'fist' as a general topic, detached from the 'Arthur' context, that is subject to playful comments that involve possible circumstances for fists, like handedness, sweaters' arm length, or, not pictured here, the colour of the individual's skin, or the recognition that the fist belongs to another character like Hulk or Spongebob. One can argue here that a topic-comment structure is established with the fist as the recurrent topic and the changing colour, shape or other circumstance around it as the comment, the new information. In grammatical terms, this would resemble a subject-predicate structure, as the predicate ascribes a feature to the subject. 
The third line of development goes towards abstraction, one of the formal cognitive operations described by Ruiz de Mendoza and Galera (2014: 86-90). Both metaphor and metonymy are based on abstraction. A formal cognitive operation is a mental mechanism by which language users can access, select, abstract, substitute, and integrate conceptual structure for the production and interpretation of linguistic (or other, my addition) communicative content (Ruiz de Mendoza and Galera 2014: 85). With the Arthur's Fist meme, the abstraction involves an iconic, i.e. metaphorical mapping of the image to different modes of representation, including, for example the layout of the scene in Lego bricks or the deconstruction of the image into the minimalist colourful dots.

Table 7: Three lines of development for Arthur's Fist meme

\begin{tabular}{|c|c|c|c|}
\hline $\begin{array}{l}\text { Grammaticalisation } \\
\text { stage }\end{array}$ & Picture & Perceived Structure & Mechanism for interpretation \\
\hline Stage 1 & $\begin{array}{l}\text { Figures } \\
14-15\end{array}$ & $\begin{array}{l}\text { Drawn image of clenched fist in } \\
\text { yellow sweater, blue trousers and } \\
\text { pink/brown background are visible }\end{array}$ & $\begin{array}{l}\text { Known Metonymy: Clenched fist as } \\
\text { symptom of an attempt to control a } \\
\text { negative emotion }\end{array}$ \\
\hline Stage 2 & $\begin{array}{l}\text { Figures } \\
16-17\end{array}$ & $\begin{array}{l}\text { Variation on representation of } \\
\text { known fist image: The fist is isolated } \\
\text { and introduced as topic }\end{array}$ & $\begin{array}{l}\text { Focus on fist as a topic. Related } \\
\text { matters like handedness, sweaters' arm } \\
\text { length etc. are offered as comments. } \\
\text { Topic-Focus arrangement, resembles } \\
\text { syntactic subject-predicate structure }\end{array}$ \\
\hline Stage 3 & $\begin{array}{l}\text { Figures } \\
18-19\end{array}$ & $\begin{array}{l}\text { Variation on representation of } \\
\text { known fist image: Changes in the } \\
\text { modality of picture representation }\end{array}$ & $\begin{array}{l}\text { Iconic mapping of the image to } \\
\text { different modes of representation } \\
\text { [Metaphor] }\end{array}$ \\
\hline
\end{tabular}

\section{Summary and conclusion}

In this paper, the popular communication form of Internet memes has been analysed in terms of their resemblance with linguistic units. The considerations started out from the observation confirmed in the literature that Internet memes are not just visual jokes dotted around the net, but that they have communicative functions, they have sign value, and they follow conventions. For each meme, a general topic area is identifiable that the picture/text combination plays with and builds up on. Through frequent usage and free creative variation, meaning elements remain relatively stable. The formal variation is generally unlimited, but often, one detail is kept throughout all variations, in order to make the meme recognisable. It has been shown that these consistent formal details behave like grammatical features, i.e. morphemes, as they carry semantics known from the full meme complex. Because the variation of memes is an undirected interactive process, the development of the grammatical features is not generally predictable. The paper discusses three popular Internet memes: Roll Safe, Scumbag Steve and Arthur's Fist. The Roll Safe meme includes a pointing gesture that can be shown to develop into a free morpheme, as it combines with new characters for variations of the meme. This was predictable as there is already a meaning convention for this gesture. In variations of the Scumbag Steve meme, the brown cap worn by the character develops into a free morpheme that combines with new characters and objects for variations of the meme. This was not predictable, as there is no 
existing convention for a brown cap to signify mean behaviour. Both the cap as a morpheme and the behaviour attributed to it by metonymy emerge from the interaction with this meme alone. With the meme Arthur's Fist, the line of development is different from the first two memes discussed. The fist is a prominent component in the picture, and it is conceivable that it could develop into a morpheme-like item, but this is not what happens in the majority of variations of the meme. Rather, there are two lines of development that both involve metacommentary on the meme: The first one introduces the fist as a topic, and gives a variety of comments on it, involving handedness, skin colour, the visibility of the fist and the like. I have argued that these instances where the fist is singled out from the correlation with the meme and taken as a topic on its own bring about topic-comment structures, which are the functional equivalent of subject-predicate structures. As for the other line of development, there are many instances that show abstractions of the image, its components and its colour scheme, by mapping it to a different mode of representation, i.e. a layout in Lego bricks or a minimalist dotted picture with the recognizable colours of the original image. For all memes discussed here, I have argued that the variations shown can be described in terms of cognitive mechanisms like metaphor and metonymy, which are operations that have been associated with grammatical changes in linguistic theory. For the first two memes, the changes can be described in terms of grammaticalisation paths, where reanalysis of a known structure leads to the development of a new morpheme. For Arthur's Fist, metonymy and metaphor can be identified as mechanisms for interpretation, but the variation in the meme does not lead to an identifiable grammaticalisation path. Given that the structures that emerge in communicative interaction are never predictable, this last example demonstrates the freedom that generally exists for interactive patterns to emerge. The objective of the approach presented here is to support a discussion that extends the description of emerging grammatical features to communicative means beyond language

\section{References}

Blackmore, S. (1999). The Meme Machine. Oxford: Oxford University Press.

Cannizzarro, S. (2016). Internet Memes as Internet Signs: A Semiotic View of Digital Culture. Sign Systems Studies $44(4), 562-586$.

Dawkins, R. (1976). The Selfish Gene. Oxford: Oxford University Press.

Diedrichsen, E. (2013a). Constructions as Memes - Interactional Function as Cultural Convention Beyond the Words. In Liedtke, F. \& Schulze, C. (Eds.): Beyond Words (pp. 283-305). Berlin: De Gruyter.

Diedrichsen, E. (2013b). From Idioms to Sentence Structures and Beyond: The Theoretical Scope of the Concept 'Construction'. In Nolan, B. \& Diedrichsen, E. (Eds.): Linking Constructions into Functional Linguistics - The Role of Constructions in Grammars (pp. 295-330). Amsterdam: John Benjamins.

Diedrichsen, E. (forthcoming). On the Interaction of Core and Emergent Common Ground in Internet Memes. To appear in Internet Pragmatics, special issue on the Pragmatics of Internet Memes.

Eco, U. (1976). A theory of semiotics. Bloomington, London: Indiana University Press.

Everett, D. (2012). Language, the cultural tool. London: Profile Books.

Feilke, H. (1996). Sprache als soziale Gestalt. Ausdruck, Prägung und die Ordnung der sprachlichen Typik, Frankfurt am Main: Suhrkamp.

Feilke, H. (1998). Idiomatische Prägung. In Barz, I. \& Öhlschläger, G. (Eds.): Zwischen Grammatik und Lexikon (pp. 69-80), Tübingen: Max Niemeyer. 
Hopper, P. J. (2011). Emergent Grammar and Temporality in Interactional Linguistics. In Auer, P. \& Pfänder, S. (Eds.): Constructions: Emerging and Emergent (pp. 22-44) Berlin/New York: De Gruyter.

Hopper, P. J. \& Traugott, E. C. (1993). Grammaticalization. Cambridge: Cambridge University Press.

Katz, Y. \& Shifman, L. (2017). Making Sense? The Structure and Meanings of Digital Memetic Nonsense. Information Communication and Society 20 (6): 825-842. DOI: 10.1080/1369118X.2017.1291702

Kecskes, I. \& Zhang, F. (2009). Activating, Seeking and Creating Common Ground: A Socio-Cognitive Approach. Pragmatics \& Cognition 17, 2, 331-355.

Kövecses, Z. (1990). Emotion Concepts. New York: Springer.

Lakoff, G. (1987). Women, Fire, and Dangerous Things. What Categories Reveal About the Mind. Chicago, London: University of Chicago Press.

Leeson, L. and Saeed, J. I. (2012). Irish Sign Language. A Cognitive Linguistic Account. Edinburgh: Edinburgh University Press.

Linell, P. (1998). Approaching Dialogue: Talk, Interaction, and Contexts in Dialogical Perspective. Amsterdam: John Benjamins.

Milner, R. M. (2012). The World Made Meme: Discourse and Identity in Paricipatory Media. PhD Dissertation, University of Kansas.

Miltner, K. (2014). 'There's No Place for Lulz on Lolcats': The Role of Genre, Gender and Group Identity in the Interpretation and Enjoyment of an Internet Meme. First Monday, 19(8). doi:10.5210/fm. v19i8.5391.

Nissenbaum, A. \& Shifman, L. (2015). Internet Memes as Contested Cultural Capital: The Case of 4chan's \B। Board. new media \& society, 1-19. doi: 10.1177/1461444815609313.

Ruiz de Mendoza Ibáñez, F. J. \& Galera Masegosa, A. (2014). Cognitive Modeling. A Linguistic Perspective. Amsterdam: Benjamins.

Shifman, L. (2013). Memes in a digital world: Reconciling with a conceptual troublemaker. Journal of ComputerMediated Communication, 18 (3), 362-377.

Ungerer, F. \& Schmid, H-J. (1996). An Introduction to Cognitive Linguistics. London / New York: Longman.

Wittgenstein, L. (1960). Philosophische Untersuchungen. In: Wittgenstein, L. Tractatus logico-philosophicus (=Schriften 1), Frankfurt am Main: Suhrkamp. 